\title{
Synthesis of Some New Arylazothiophene and Arylazopyrazole Derivatives as Antitumor Agents
}

\author{
Ahmed Ali Fadda*, E. Abdel-Latif, Rasha E. El-Mekawy \\ Chemistry Department, Faculty of Science, Mansoura University, Mansoura, Egypt. \\ Email: ${ }^{*}$ afadda2@yahoo.com \\ Received January $14^{\text {th }}, 2012$; revised February $20^{\text {th }}, 2012$; accepted March $4^{\text {th }}, 2012$
}

\begin{abstract}
The starting 1-phenylbutane-1,3-dione (1) was used as key intermediate for the synthesis of several new thiophene and pyrazole derivatives. The newly synthesized compounds were evaluated for in vitro cytotoxicity against an Ehrlich ascites cells and in vivo cytotoxicity for compound 10d using EAC assay and 5-fluorouracil is used as reference drug. Compounds 7c, $\mathbf{e}$ and 10c, $\mathbf{d}$ showed significant activity in certain cancer cell and have been targeted for further studies, compound 10d is more effective and showed the highest activity. Structures of the newly prepared compounds were confirmed by both spectral, analytical data and molecular calculations.
\end{abstract}

Keywords: Benzoylacetone; Phenylisothiocyanate; Thiophene; Pyrazole; Thiocarbamoyl; Cytotoxic Agents

\section{Introduction}

Aryl isothiocyanates are versatile reagents which have been used as synthetic intermediate to prepare biologically active heterocyclic compounds [1]. As a part of our program of developing new, simple and efficient procedures for the synthesis of new aromatic compounds using readily available aryl isothiocyanates, we have recently affected recyclization of thiocarbamoyl into pyrazoles and thiazoles [2-5]. This procedure appears to be a fundamental type of type of thiocarbamoyl transformation into pyrazole ring.

In continuation of our studies on the chemistry of thiocarbamoyl and active methylene compounds $[6,7]$ and as a part of our program directed toward developing new approaches to a variety of heterocycles exhibited antitumor activities [8,9], we report here the scope and applicability of 1-phenylbutane-1,3-dione (1) as a unique precursor for the synthesis of some new pyrazole, thiophene and thiocarbamoyl derivatives and their behavior towards different reagents.

\section{Experimental}

\subsection{General}

All melting points are in degree centigrade and were determined on Gallenkamp electric melting point apparatus. The IR spectra $v / \mathrm{cm}^{-1}(\mathrm{KBr})$ were recorded on Perkin Elmer Infrared Spectrophotometer Model 157, Grating.

"Corresponding author.
The ${ }^{1}$ H-NMR spectra were obtained on a Varian Spectrophotometer at $200 \mathrm{MHz}$ using TMS as an internal reference and DMSO- $d_{6}$ as solvent. The mass spectra (EI) were recorded on $70 \mathrm{eV}$ with Kratos MS equipment and/ or a Varian MAT 311 A Spectrometer. Elemental analyses $(\mathrm{C}, \mathrm{H}$, and $\mathrm{N})$ were carried out at the Micro Analytical Center of Cairo Univ., Giza, Egypt.

\subsubsection{Synthesis of Thiocarbamoyl Derivative 3}

To a cold suspension of potassium hydroxide $(1.4 \mathrm{~g}, 25$ mmol) in DMF (30 $\mathrm{mL})$ was added the benzoyl acetone (4.05 g, $25 \mathrm{mmol})$, followed by phenyl isothiocyanate ( $3.375 \mathrm{~g}, 25 \mathrm{mmol})$. The mixture was stirred overnight at room temperature and then poured onto ice-cold water. Acidification using dilute $\mathrm{HCl}$ until the medium becomes acidic gave solid product $\mathbf{3}$ which was filtered off, washed with water, dried and crystallized from aqueous ethanol to give compound 3.

Yield $100 \% ; \mathrm{mp} 140^{\circ} \mathrm{C}$; IR $(\mathrm{KBr}): v / \mathrm{cm}^{-1}=3229$, $3125,1600,1283 \mathrm{~cm}^{-1}(\mathrm{OH}, \mathrm{NH}, \mathrm{C}=\mathrm{O}, \mathrm{C}=\mathrm{S}) ;{ }^{1} \mathrm{H}$ NMR (DMSO): $\delta_{\mathrm{ppm}}=2.5\left(\mathrm{~s}, 3 \mathrm{H}, \mathrm{CH}_{3}\right), 7.1-7.5(\mathrm{~m}, 10 \mathrm{H}, \mathrm{Ar})$, $11.9(\mathrm{~s}, 1 \mathrm{H}, \mathrm{NH}) ; \operatorname{EIMS}(\mathrm{m} / \mathrm{z})(\%)=297\left(\mathrm{M}^{+}, 14\right), 255$ (17), 222 (25). Anal. for $\mathrm{C}_{17} \mathrm{H}_{15} \mathrm{NO}_{2} \mathrm{~S}$ (297.4): calcd.: C 68.66, H 5.08\%; found: C 68.50, H 4.90\%.

\subsubsection{Coupling of 3 with Aromatic Diazonium Salts: Formation of Monoazothiocarbamoyl Derivatives 4a-e}

General procedure: A well stirred solution of aromatic amines $(20 \mathrm{mmol})$ in concentrated $\mathrm{HCl}(6 \mathrm{~mL})$ and water 
$(4 \mathrm{~mL})$ was cooled in an ice bath and diazotized with a solution of sodium nitrite $(1.39 \mathrm{~g}, 20 \mathrm{mmol})$ in water $(5$ $\mathrm{mL})$.

The above cold diazonium solution was added drop wise to a well stirred cold solution of 3 in ethanol $(10 \mathrm{~mL})$ containing sodium acetate $(1.75 \mathrm{~g}, 20 \mathrm{mmol})$. The reaction mixture was stirred for $1-2 \mathrm{~h}$ until reach complete coupling reaction. The crude product was filtered off, dried well and recrystallized from ethanol.

4a, Yield $80 \%$; mp $140^{\circ} \mathrm{C}$; IR $(\mathrm{KBr}): \mathrm{v} / \mathrm{cm}^{-1}=3250$, 1640, $1280 \mathrm{~cm}^{-1}(\mathrm{NH}, \mathrm{C}=\mathrm{O}, \mathrm{C}=\mathrm{S}) ;{ }^{1} \mathrm{H}$ NMR $\left(\mathrm{CDCl}_{3}\right)$ : $\delta_{\mathrm{ppm}}=6.8-7.8(\mathrm{~m}, 15 \mathrm{H}, \mathrm{Ar}), 13.9$ and $16.4(\mathrm{~s}, 2 \mathrm{H}$, 2NH); EIMS $(\mathrm{m} / \mathrm{z})(\%)=359\left(\mathrm{M}^{+}, 19\right), 239(13), 161$ (4.5), 105 (80), 77 (100). Anal. for $\mathrm{C}_{21} \mathrm{H}_{17} \mathrm{~N}_{3} \mathrm{OS}$ (359.4): calcd.: C 70.17, H 4.77\%; found: C 70.00, H 4.60\%.

4b, Yield $88 \%$; mp $174^{\circ} \mathrm{C}$; IR $(\mathrm{KBr}): v / \mathrm{cm}^{-1}=3250$, 2919, 1640, $1280 \mathrm{~cm}^{-1}\left(\mathrm{NH}, \mathrm{CH}_{3}, \mathrm{C}=\mathrm{O}, \mathrm{C}=\mathrm{S}\right) ;{ }^{1} \mathrm{H}$ NMR (DMSO): $\delta_{\mathrm{ppm}}=2.3\left(\mathrm{~s}, 3 \mathrm{H}, \mathrm{CH}_{3}\right), 7.1-8.2(\mathrm{~m}, 14 \mathrm{H}, \mathrm{Ar})$, 10.7 and $12.3(\mathrm{~s}, 2 \mathrm{H}, 2 \mathrm{NH})$; EIMS $(\mathrm{m} / \mathrm{z})(\%)=373\left(\mathrm{M}^{+}\right.$, 15), 239 (12), 105 (73), 77 (96). Anal. for $\mathrm{C}_{22} \mathrm{H}_{19} \mathrm{~N}_{3} \mathrm{OS}$ (373.5): calcd.: C 70.75, H 5.13\%; found: C 70.75, H $5.08 \%$.

4c, Yield $85 \%$; mp $172^{\circ} \mathrm{C}$; IR (KBr): v/cm ${ }^{-1}=3250$, 2937, 1640, $1280 \mathrm{~cm}^{-1}\left(\mathrm{NH}, \mathrm{CH}_{3}, \mathrm{C}=\mathrm{O}, \mathrm{C}=\mathrm{S}\right) ;{ }^{1} \mathrm{H}$ NMR (DMSO): $\delta_{\mathrm{ppm}}=4.0\left(\mathrm{~s}, 3 \mathrm{H}, \mathrm{CH}_{3}\right), 7.0-8.7(\mathrm{~m}, 14 \mathrm{H}, \mathrm{Ar})$, 12.6 and $16.4(\mathrm{~s}, 2 \mathrm{H}, 2 \mathrm{NH})$; EIMS $(\mathrm{m} / \mathrm{z})(\%)=389\left(\mathrm{M}^{+}\right.$, 24), 239 (15), 161 (18), 105 (80), 77 (100). Anal. for

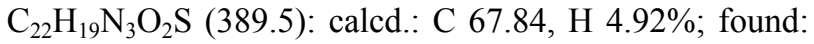
C 67.83, H 4.80\%.

4d, Yield $78 \%$; mp $218^{\circ} \mathrm{C}$; IR $(\mathrm{KBr}): v / \mathrm{cm}^{-1}=3250$, 1640, 1550, $1280 \mathrm{~cm}^{-1}\left(\mathrm{NH}, \mathrm{C}=\mathrm{O}, \mathrm{NO}_{2}, \mathrm{C}=\mathrm{S}\right) ;{ }^{1} \mathrm{H}$ NMR (DMSO): $\delta_{\mathrm{ppm}}=6.8-7.9(\mathrm{~m}, 14 \mathrm{H}, \mathrm{Ar}), 12.5$ and $14.8(\mathrm{~s}$, $2 \mathrm{H}, 2 \mathrm{NH}) ; \operatorname{EIMS}(\mathrm{m} / \mathrm{z})(\%)=404\left(\mathrm{M}^{+}, 18\right), 402(7), 239$ (30), 161 (10), 105 (100), 77 (97). Anal. for $\mathrm{C}_{21} \mathrm{H}_{16} \mathrm{~N}_{4} \mathrm{O}_{3} \mathrm{~S}$ (404.4): calcd.: C 62.36, H 3.99\%; found: C 62.30, H 3.99\%.

4e, Yield $72 \% ; \mathrm{mp} 200^{\circ} \mathrm{C}$; IR $(\mathrm{KBr}): v / \mathrm{cm}^{-1}=3250$, 1640, $1280 \mathrm{~cm}^{-1}(\mathrm{NH}, \mathrm{C}=\mathrm{O}, \mathrm{C}=\mathrm{S}) ;{ }^{1} \mathrm{H} \mathrm{NMR}\left(\mathrm{CDCl}_{3}\right)$ : $\delta_{\mathrm{ppm}}=7.0-7.6(\mathrm{~m}, 14 \mathrm{H}, \mathrm{Ar}), 10.2$ and $14.6(\mathrm{~s}, 2 \mathrm{H}, 2 \mathrm{NH})$; $\operatorname{EIMS}(\mathrm{m} / \mathrm{z})(\%)=393\left(\mathrm{M}^{+}, 17\right), 239(20), 125(10), 105$ (75), 77 (100). Anal. for $\mathrm{C}_{21} \mathrm{H}_{16} \mathrm{~N}_{3} \mathrm{OSCl}$ (393.9): calcd.: C 64.03, H 4.09\%; found: C 64.00, H 4.03\%.

\subsubsection{Synthesis of the Acyclic Intermediate 8a, 9a, 11a and 13a}

Equimolecular quantities of $\mathbf{4 a}(3.59 \mathrm{~g}, 10 \mathrm{mmol})$ in ethanol containing potassium carbonate $(1.39 \mathrm{~g}, 10 \mathrm{mmol})$ and phenacyl bromide and/or ethyl bromoacetate and/or chloroacetonitrile and/or chloroacetone were stirred for 6 hrs at room temperature, then left to stand at the same temperature for $24 \mathrm{~h}$. The separated solid product was washed with water, dried and crystallized from ethanol to give 8a, 9a, 11a and 13a, respectively.

8a, Yield $58 \%$; mp $153^{\circ} \mathrm{C}$; IR (KBr): $v / \mathrm{cm}^{-1}=3150$,
(1640 and 1623), $1600 \mathrm{~cm}^{-1}(\mathrm{NH}$, two $\mathrm{C}=\mathrm{O}, \mathrm{N}=\mathrm{N}) ;{ }^{1} \mathrm{H}$ NMR (DMSO): $\delta_{\mathrm{ppm}}=4.2\left(\mathrm{~s}, 2 \mathrm{H}, \mathrm{CH}_{2}\right), 6.8-7.9(\mathrm{~m}$, $20 \mathrm{H}, \mathrm{Ar}), 10.5(\mathrm{~s}, 1 \mathrm{H}, \mathrm{NH})$. Anal. for $\mathrm{C}_{29} \mathrm{H}_{23} \mathrm{~N}_{3} \mathrm{O}_{2} \mathrm{~S}$ (477.5): calcd.: C 72.94, H 4.85\%; found: C 72.94, H $4.79 \%$.

9a, Yield $60 \% ; \mathrm{mp} 170^{\circ} \mathrm{C}$; IR $(\mathrm{KBr}): v / \mathrm{cm}^{-1}=3150$, (170 and 1625), $1600 \mathrm{~cm}^{-1}(\mathrm{NH}$, two $\mathrm{C}=\mathrm{O}, \mathrm{N}=\mathrm{N}) ;{ }^{1} \mathrm{H}$ NMR (DMSO): $\delta_{\mathrm{ppm}}=1.3\left(\mathrm{t}, 3 \mathrm{H}, \mathrm{CH}_{3}\right), 3.7\left(\mathrm{~s}, 2 \mathrm{H}, \mathrm{CH}_{2}\right)$, 4.3 (q, 2H, $\left.\mathrm{CH}_{2}\right), 6.8-7.7(\mathrm{~m}, 15 \mathrm{H}, \mathrm{Ar}), 12.9(\mathrm{~s}, 1 \mathrm{H}$, $\mathrm{NH})$; $\operatorname{EIMS}(\mathrm{m} / \mathrm{z})(\%)=445\left(\mathrm{M}^{+}, 10\right)$. Anal. for

$\mathrm{C}_{25} \mathrm{H}_{23} \mathrm{~N}_{3} \mathrm{O}_{3} \mathrm{~S}$ (445.5): calcd.: C 67.40, H 5.20\%; found: $\mathrm{C} 67.30$, H $5.00 \%$.

11a, Yield $60 \% ; \mathrm{mp} 160^{\circ} \mathrm{C}$; IR $(\mathrm{KBr}): v / \mathrm{cm}^{-1}=3200$, 2220, $1695 \mathrm{~cm}^{-1}(\mathrm{NH}, \mathrm{CN}, \mathrm{C}=\mathrm{O}) ;{ }^{1} \mathrm{H}$ NMR (DMSO): $\delta_{\mathrm{ppm}}=3.23\left(\mathrm{~s}, 2 \mathrm{H}, \mathrm{CH}_{2}\right), 7.5-8.0(\mathrm{~m}, 15 \mathrm{H}, \mathrm{Ar}), 14.2(\mathrm{~s}$, $1 \mathrm{H}, \mathrm{NH})$; $\operatorname{EIMS}(\mathrm{m} / \mathrm{z})(\%)=398\left(\mathrm{M}^{+}, 90\right)$. Anal. for $\mathrm{C}_{23} \mathrm{H}_{18} \mathrm{~N}_{4} \mathrm{OS}$ (398.48): calcd.: $\mathrm{C} 69.33$, H 4.55\%; found: C 69.33, H 4.55\%.

13a, Yield $76 \%$; mp $178^{\circ} \mathrm{C}$; IR (KBr): $v / \mathrm{cm}^{-1}=3250$, 1660, $1600 \mathrm{~cm}^{-1}(\mathrm{NH}, \mathrm{C}=\mathrm{O}, \mathrm{N}=\mathrm{N}) ;{ }^{1} \mathrm{H}$ NMR (DMSO): $\delta_{\mathrm{ppm}}=2.5\left(\mathrm{~s}, 3 \mathrm{H}, \mathrm{CH}_{3}\right), 3.2\left(\mathrm{~s}, 2 \mathrm{H}, \mathrm{CH}_{2}\right), 7.5-8.0(\mathrm{~m}$, $15 \mathrm{H}, \mathrm{Ar}), 14.5(\mathrm{~s}, 1 \mathrm{H}, \mathrm{NH})$. Anal. for $\mathrm{C}_{23} \mathrm{H}_{19} \mathrm{~N}_{3} \mathrm{O}_{2} \mathrm{~S}$ (401.49): calcd.: C 68.81, H 4.77\%; found: C 68.80, H $4.76 \%$.

\subsubsection{Synthesis of Thiophene Derivatives}

Pathway 1) A mixture of equimolecular amounts of 4a-e and $\alpha$-halo compounds $(10 \mathrm{mmol})$ was stirred in DMF $(20 \mathrm{~mL})$ containing potassium carbonate $(1.39 \mathrm{~g}, 10$ $\mathrm{mmol}$ ) overnight. The reaction mixture was poured onto ice-cold water, acidified by dilute $\mathrm{HCl}$, filtered off and recrystallized from ethanol to give the corresponding thiophene derivatives.

Pathway 2) Refluxing the acyclic intermediate 8a, 9a, 11a and 13a in ethanol $(20 \mathrm{~mL})$ containing a catalytic amount of TEA for $3 \mathrm{~h}$ afforded the corresponding thiophene derivatives 7a, 10a, 12a and 14a.

Compounds 7a-e, 10a-e, 12a-e and 14a-e were obtained according to pathway 1.

7a, Yield $68 \% ; \mathrm{mp} 180^{\circ} \mathrm{C}$; IR $(\mathrm{KBr}): \mathrm{v} / \mathrm{cm}^{-1}=3150$, 1660, $1600 \mathrm{~cm}^{-1}(\mathrm{NH}, \mathrm{C}=\mathrm{O}, \mathrm{N}=\mathrm{N}) ;{ }^{1} \mathrm{H} \mathrm{NMR}\left(\mathrm{CDCl}_{3}\right)$ : $\delta_{\mathrm{ppm}}=7.4-8.0(\mathrm{~m}, 20 \mathrm{H}, \mathrm{Ar}), 10.2(\mathrm{~s}, 1 \mathrm{H}, \mathrm{NH})$; EIMS $(m / z)(\%)=459\left(\mathrm{M}^{+}, 10\right), 428$ (18), 105(20), 77 (80). Anal. for $\mathrm{C}_{29} \mathrm{H}_{21} \mathrm{~N}_{3} \mathrm{OS}$ (459.6): calcd.: C 75.79, $\mathrm{H} 4.61 \%$; found: C 75.79, $\mathrm{H} 4.59 \%$.

7b, Yield $60 \%$; mp $200^{\circ} \mathrm{C}$; IR $(\mathrm{KBr}): v / \mathrm{cm}^{-1}=3321$, 2919, 1660, $1602 \mathrm{~cm}^{-1}\left(\mathrm{NH}, \mathrm{CH}_{3}, \mathrm{C}=\mathrm{O}, \mathrm{N}=\mathrm{N}\right) ;{ }^{1} \mathrm{H} \mathrm{NMR}$ (DMSO): $\delta_{\mathrm{ppm}}=2.3\left(\mathrm{~s}, 3 \mathrm{H}, \mathrm{CH}_{3}\right), 7.0-7.8(\mathrm{~m}, 19 \mathrm{H}, \mathrm{Ar})$, $14.2(\mathrm{~s}, 1 \mathrm{H}, \mathrm{NH})$; $\operatorname{EIMS}(\mathrm{m} / \mathrm{z})(\%)=473\left(\mathrm{M}^{+}, 70\right), 472$ (18), 239 (20), 105 (25), 77 (80). Anal. for $\mathrm{C}_{30} \mathrm{H}_{23} \mathrm{~N}_{3} \mathrm{OS}$ (473.6): calcd.: C 76.08, H 4.90\%; found: C 76.00, H $4.80 \%$

7c, Yield $64 \%$; mp $210^{\circ} \mathrm{C}$; IR $(\mathrm{KBr}): \mathrm{v} / \mathrm{cm}^{-1}=3344$, 2923, 1684, $1598 \mathrm{~cm}^{-1}\left(\mathrm{NH}, \mathrm{CH}_{3}, \mathrm{C}=\mathrm{O}, \mathrm{N}=\mathrm{N}\right) ;{ }^{1} \mathrm{H}$ NMR 
(DMSO): $\delta_{\mathrm{ppm}}=3.9\left(\mathrm{~s}, 3 \mathrm{H}, \mathrm{CH}_{3}\right), 6.9-7.5(\mathrm{~m}, 19 \mathrm{H}, \mathrm{Ar})$, $12.3(\mathrm{~s}, 1 \mathrm{H}, \mathrm{NH}) ; \operatorname{EIMS}(\mathrm{m} / \mathrm{z})(\%)=489\left(\mathrm{M}^{+}, 68\right), 458$ (40), 368 (20), 105 (28), 77 (100). Anal. for

$\mathrm{C}_{30} \mathrm{H}_{23} \mathrm{~N}_{3} \mathrm{O}_{2} \mathrm{~S}$ (489.6): calcd.: C 73.60, H 4.74\%; found: C 73.60, H 4.60\%.

7d, Yield $74 \%$; $\mathrm{mp} 226^{\circ} \mathrm{C}$; IR $(\mathrm{KBr}): v / \mathrm{cm}^{-1}=3342$, $1680,1549,1590 \mathrm{~cm}^{-1}\left(\mathrm{NH}, \mathrm{C}=\mathrm{O}, \mathrm{NO}_{2}, \mathrm{~N}=\mathrm{N}\right) ;{ }^{1} \mathrm{H} \mathrm{NMR}$ $\left(\mathrm{CDCl}_{3}\right): \delta_{\mathrm{ppm}}=7.0-8.4(\mathrm{~m}, 19 \mathrm{H}, \mathrm{Ar}), 10.8(\mathrm{~s}, 1 \mathrm{H}, \mathrm{NH})$; EIMS $(\mathrm{m} / \mathrm{z})(\%)=504\left(\mathrm{M}^{+}, 80\right), 501(24), 456(16), 105$ (70), 77 (90). Anal. for $\mathrm{C}_{29} \mathrm{H}_{20} \mathrm{~N}_{4} \mathrm{O}_{3} \mathrm{~S}$ (504.6): calcd.: C 69.30, H 4.00\%; found: C 69.00, H 4.00\%.

7e, Yield $55 \%$; mp $160^{\circ} \mathrm{C}$; IR $(\mathrm{KBr}): \mathrm{v} / \mathrm{cm}^{-1}=3320$, $1660,1600 \mathrm{~cm}^{-1}(\mathrm{NH}, \mathrm{C}=\mathrm{O}, \mathrm{N}=\mathrm{N}) ;{ }^{1} \mathrm{H}$ NMR $(\mathrm{DMSO})$ : $\delta_{\mathrm{ppm}}=(7.0$ - 7.6) (m, 19H, Ar), $14.2(\mathrm{~s}, 1 \mathrm{H}, \mathrm{NH})$; EIMS $(\mathrm{m} / \mathrm{z})(\%)=494\left(\mathrm{M}^{+}, 60\right), 492(18), 105(70)$. Anal. for $\mathrm{C}_{29} \mathrm{H}_{20} \mathrm{~N}_{3} \mathrm{OSCl}$ (494): calcd.: C 70.51, H 4.08\%; found: $\mathrm{C}$ $70.51, \mathrm{H} 4.08 \%$.

10a, Yield 55\%; mp $180^{\circ} \mathrm{C}$; IR $(\mathrm{KBr}): \mathrm{v} / \mathrm{cm}^{-1}=3327$, $1700,1594 \mathrm{~cm}^{-1}(\mathrm{NH}, \mathrm{C}=\mathrm{O}, \mathrm{N}=\mathrm{N}) ;{ }^{1} \mathrm{H}$ NMR $\left(\mathrm{CDCl}_{3}\right)$ : $\delta_{\mathrm{ppm}}=1.1\left(\mathrm{t}, 3 \mathrm{H}, \mathrm{CH}_{3}\right), 4.1\left(\mathrm{q}, 2 \mathrm{H}, \mathrm{CH}_{2}\right), 7.0-7.6(\mathrm{~m}$, $15 \mathrm{H}, \mathrm{Ar}), 14.3$ (s, 1H, NH); EIMS $(\mathrm{m} / \mathrm{z})(\%)=427\left(\mathrm{M}^{+}\right.$, 80), 105 (70), 77 (90). Anal. for $\mathrm{C}_{25} \mathrm{H}_{21} \mathrm{~N}_{3} \mathrm{O}_{2} \mathrm{~S}$ (427.5): calcd.: C 70.24, H 4.95\%; found: C 70.19, H 4.95\%.

10b, Yield $75 \%$; $\mathrm{mp} 170^{\circ} \mathrm{C}$; IR $(\mathrm{KBr}): v / \mathrm{cm}^{-1}=3427$, $1734,1580 \mathrm{~cm}^{-1}(\mathrm{NH}, \mathrm{C}=\mathrm{O}, \mathrm{N}=\mathrm{N}) ;{ }^{1} \mathrm{H}$ NMR $\left(\mathrm{CDCl}_{3}\right)$ : $\delta_{\text {ppm }}=1.1\left(\mathrm{t}, 3 \mathrm{H}, \mathrm{CH}_{3}\right), 2.3\left(\mathrm{~s}, 3 \mathrm{H}, \mathrm{CH}_{3}\right), 4.2(\mathrm{q}, 2 \mathrm{H}$, $\left.\mathrm{CH}_{2}\right), 7.0-7.6(\mathrm{~m}, 14 \mathrm{H}, \mathrm{Ar}), 14.1(\mathrm{~s}, 1 \mathrm{H}, \mathrm{NH})$; EIMS $(\mathrm{m} / \mathrm{z})(\%)=441\left(\mathrm{M}^{+}, 50\right), 105\left(\mathrm{M}^{+}, 70\right)$. Anal. for $\mathrm{C}_{26} \mathrm{H}_{23} \mathrm{~N}_{3} \mathrm{O}_{2} \mathrm{~S}$ (441.5): calcd.: C 70.72, H 5.25\%; found: C 70.72 , H $5.25 \%$.

10c, Yield $62 \%$; $\mathrm{mp} 140^{\circ} \mathrm{C}$; IR $(\mathrm{KBr}): \mathrm{v} / \mathrm{cm}^{-1}=3344$, 1684, $1608 \mathrm{~cm}^{-1}$ (NH, $\left.\mathrm{C}=\mathrm{O}, \mathrm{N}=\mathrm{N}\right) ;{ }^{1} \mathrm{H}$ NMR (DMSO): $\delta_{\mathrm{ppm}}=1.3\left(\mathrm{t}, 3 \mathrm{H}, \mathrm{CH}_{3}\right), 3.9\left(\mathrm{~s}, 3 \mathrm{H}, \mathrm{CH}_{3}\right), 4.2(\mathrm{q}, 2 \mathrm{H}$, $\left.\mathrm{CH}_{2}\right), 7.0$ - $7.6(\mathrm{~m}, 14 \mathrm{H}, \mathrm{Ar}), 14.2(\mathrm{~s}, 1 \mathrm{H}, \mathrm{NH})$; EIMS $(\mathrm{m} / \mathrm{z})(\%)=457\left(\mathrm{M}^{+}, 10\right), 426(12), 105$ (70). Anal. for $\mathrm{C}_{26} \mathrm{H}_{23} \mathrm{~N}_{3} \mathrm{O}_{3} \mathrm{~S}$ (457.5): calcd.: $\mathrm{C} 68.25$, H 5.07\%; found: C 68.25 , H $5.07 \%$.

10d, Yield $70 \%$; mp $190^{\circ} \mathrm{C}$; IR (KBr): $v / \mathrm{cm}^{-1}=3345$, $1718,1540,1594 \mathrm{~cm}^{-1}\left(\mathrm{NH}, \mathrm{C}=\mathrm{O}, \mathrm{NO}_{2}, \mathrm{~N}=\mathrm{N}\right) ;{ }^{1} \mathrm{H}$ NMR $\left(\mathrm{CDCl}_{3}\right): \delta_{\mathrm{ppm}}=1.1\left(\mathrm{t}, 3 \mathrm{H}, \mathrm{CH}_{3}\right), 4.1\left(\mathrm{q}, 2 \mathrm{H}, \mathrm{CH}_{2}\right), 7.3-$ $8.4(\mathrm{~m}, 14 \mathrm{H}, \mathrm{Ar}), 14.9(\mathrm{~s}, 1 \mathrm{H}, \mathrm{NH})$; $\operatorname{EIMS}(\mathrm{m} / \mathrm{z})(\%)=$ $472\left(\mathrm{M}^{+}, 10\right), 426$ (24), 105 (77), 77 (89). Anal. for $\mathrm{C}_{25} \mathrm{H}_{20} \mathrm{~N}_{4} \mathrm{O}_{4} \mathrm{~S}$ (472.5): calcd.: C 63.55, H 4.27\%; found: C $63.55, \mathrm{H} 4.00 \%$.

10e, Yield $57 \%$; $\mathrm{mp} 180^{\circ} \mathrm{C}$; IR $(\mathrm{KBr}): \mathrm{v} / \mathrm{cm}^{-1}=3316$, $1715,1690 \mathrm{~cm}^{-1}(\mathrm{NH}, \mathrm{C}=\mathrm{O}, \mathrm{N}=\mathrm{N}) ;{ }^{1} \mathrm{H}$ NMR $\left(\mathrm{CDCl}_{3}\right)$ : $\delta_{\text {ppm }}=1.1\left(\mathrm{t}, 3 \mathrm{H}, \mathrm{CH}_{3}\right), 4.1\left(\mathrm{q}, 2 \mathrm{H}, \mathrm{CH}_{2}\right), 7.2-7.6(\mathrm{~m}$, $14 \mathrm{H}, \mathrm{Ar}), 14.1(\mathrm{~s}, 1 \mathrm{H}, \mathrm{NH})$; EIMS $(m / z)(\%)=462\left(\mathrm{M}^{+}\right.$, 80). Anal. for $\mathrm{C}_{25} \mathrm{H}_{20} \mathrm{~N}_{3} \mathrm{O}_{2} \mathrm{SCl}$ (462): calcd.: $\mathrm{C} 65.00, \mathrm{H}$ 4.36\%; found: C $65.00, \mathrm{H} 4.30 \%$.

12a, Yield $52 \%$; $\mathrm{mp} 204^{\circ} \mathrm{C}$; IR $(\mathrm{KBr}): \mathrm{v} / \mathrm{cm}^{-1}=3327$, 2196, $1595(\mathrm{NH}, \mathrm{CN}, \mathrm{N}=\mathrm{N}) ;{ }^{1} \mathrm{H}$ NMR (DMSO): $\delta_{\mathrm{ppm}}=$ $7.31-7.56(\mathrm{~m}, 15 \mathrm{H}, \mathrm{Ar}), 14.2$ (s, 1H, NH); EIMS $(\mathrm{m} / \mathrm{z})$ $(\%)=380\left(\mathrm{M}^{+}, 86\right), 365(15), 105(77), 77$ (100). Anal. for $\mathrm{C}_{23} \mathrm{H}_{16} \mathrm{~N}_{4} \mathrm{~S}$ (380.5): calcd.: C 72.61, H 4.24\%; found: C 72.61, H $4.00 \%$.

12b, Yield 58\%; mp $176^{\circ} \mathrm{C}$; IR (KBr): $v / \mathrm{cm}^{-1}=3324$, $2199 \mathrm{~cm}^{-1}(\mathrm{NH}, \mathrm{CN}) ;{ }^{1} \mathrm{H}$ NMR (DMSO): $\delta_{\mathrm{ppm}}=2.3(\mathrm{~s}$, $\left.3 \mathrm{H}, \mathrm{CH}_{3}\right), 7.3-7.6(\mathrm{~m}, 14 \mathrm{H}, \mathrm{Ar}), 13.8(\mathrm{~s}, 1 \mathrm{H}, \mathrm{NH})$; EIMS $(\mathrm{m} / \mathrm{z})(\%)=394\left(\mathrm{M}^{+}, 88\right), 379(18), 105(78)$. Anal. for $\mathrm{C}_{24} \mathrm{H}_{18} \mathrm{~N}_{4} \mathrm{~S}$ (394.3): calcd.: C 73.07, H 4.60\%; found: C 73.00, H $4.50 \%$.

12c, Yield $53 \%$; mp $184^{\circ} \mathrm{C}$; IR $(\mathrm{KBr}): v / \mathrm{cm}^{-1}=3345$, $2201 \mathrm{~cm}^{-1}(\mathrm{NH}, \mathrm{CN}) ;{ }^{1} \mathrm{H}$ NMR (DMSO): $\delta_{\mathrm{ppm}}=4.2(\mathrm{~s}$, $\left.3 \mathrm{H}, \mathrm{CH}_{3}\right), 7.2-8.0(\mathrm{~m}, 14 \mathrm{H}, \mathrm{Ar}), 14.2(\mathrm{~s}, 1 \mathrm{H}, \mathrm{NH})$; EIMS $(m / z)(\%)=410\left(\mathbf{M}^{+}, 88\right), 381(70), 105(70)$. Anal. for $\mathrm{C}_{24} \mathrm{H}_{18} \mathrm{~N}_{4} \mathrm{OS}$ (410.5): calcd.: C 70.22, H 4.42\%; found: C $70.00, \mathrm{H} 4.00 \%$.

12d, Yield $57 \%$; mp $210^{\circ} \mathrm{C}$; IR (KBr): $v / \mathrm{cm}^{-1}=3319$, 2202, 1593, $1531 \mathrm{~cm}^{-1}\left(\mathrm{NH}, \mathrm{CN}, \mathrm{N}=\mathrm{N}, \mathrm{NO}_{2}\right) ;{ }^{1} \mathrm{H} \mathrm{NMR}$ $\left(\mathrm{CDCl}_{3}\right): \delta_{\mathrm{ppm}}=7.3-8.0(\mathrm{~m}, 14 \mathrm{H}, \mathrm{Ar}), 14.3(\mathrm{~s}, 1 \mathrm{H}, \mathrm{NH})$; EIMS $(\mathrm{m} / \mathrm{z})(\%)=425\left(\mathrm{M}^{+}, 100\right), 379(24), 105(70)$. Anal. for $\mathrm{C}_{23} \mathrm{H}_{15} \mathrm{~N}_{5} \mathrm{O}_{2} \mathrm{~S}$ (425.5): calcd.: C 64.93, H 3.55\%; found: C $64.80, \mathrm{H} 3.40 \%$.

12e, Yield $83 \%$; $\mathrm{mp} 190^{\circ} \mathrm{C}$; IR $(\mathrm{KBr}): \mathrm{v} / \mathrm{cm}^{-1}=3420$, 2198, $1568 \mathrm{~cm}^{-1}(\mathrm{NH}, \mathrm{CN}, \mathrm{N}=\mathrm{N}) ;{ }^{1} \mathrm{H}$ NMR $\left(\mathrm{CDCl}_{3}\right)$ : $\delta_{\mathrm{ppm}}=7.2-8.5(\mathrm{~m}, 14 \mathrm{H}, \mathrm{Ar}), 14.3(\mathrm{~s}, 1 \mathrm{H}, \mathrm{NH})$; EIMS $(m / z)(\%)=414\left(\mathrm{M}^{+}, 68\right)$. Anal. for $\mathrm{C}_{23} \mathrm{H}_{15} \mathrm{~N}_{4} \mathrm{SCl}(414.9)$ : calcd.: C 66.58, H 3.55\%; found: C 66.58, H 3.50\%.

14a, Yield $74 \% ; \mathrm{mp} 140^{\circ} \mathrm{C}$; IR $(\mathrm{KBr}): \mathrm{v} / \mathrm{cm}^{-1}=3337$, $1645,1597 \mathrm{~cm}^{-1}(\mathrm{NH}, \mathrm{C}=\mathrm{O}, \mathrm{N}=\mathrm{N}) ;{ }^{1} \mathrm{H}$ NMR $\left(\mathrm{CDCl}_{3}\right)$ : $\delta_{\mathrm{ppm}}=2.1\left(\mathrm{~s}, 3 \mathrm{H}, \mathrm{CH}_{3}\right), 7.3-7.8(\mathrm{~m}, 15 \mathrm{H}, \mathrm{Ar}), 14.2(\mathrm{~s}$, $1 \mathrm{H}, \mathrm{NH})$; $\operatorname{EIMS}(\mathrm{m} / \mathrm{z})(\%)=397\left(\mathrm{M}^{+}, 78\right)$. Anal. for $\mathrm{C}_{24} \mathrm{H}_{19} \mathrm{~N}_{3} \mathrm{OS}$ (397.5): calcd.: C 72.52, H 4.82\%; found: C $72.40, \mathrm{H} 4.70 \%$.

14b, Yield $50.5 \%$; $\mathrm{mp} 140^{\circ} \mathrm{C}$; IR $(\mathrm{KBr}): \mathrm{v} / \mathrm{cm}^{-1}=3345$, $1645,1598(\mathrm{NH}, \mathrm{C}=\mathrm{O}, \mathrm{N}=\mathrm{N}) ;{ }^{1} \mathrm{H}$ NMR $\left(\mathrm{CDCl}_{3}\right): \delta_{\mathrm{ppm}}=$ $1.9\left(\mathrm{~s}, 3 \mathrm{H}, \mathrm{CH}_{3}\right), 2.3\left(\mathrm{~s}, 3 \mathrm{H}, \mathrm{CH}_{3}\right), 7.1-7.6(\mathrm{~m}, 14 \mathrm{H}, \mathrm{Ar})$, $14.1(\mathrm{~s}, 1 \mathrm{H}, \mathrm{NH})$; EIMS $(\mathrm{m} / \mathrm{z})(\%)=411\left(\mathrm{M}^{+}, 15\right)$. Anal. for $\mathrm{C}_{25} \mathrm{H}_{21} \mathrm{~N}_{3} \mathrm{OS}$ (411.5): calcd.: C 72.97, H 5.14\%; found: C 72.97, H 5.00\%.

14c, Yield 63\%; mp $192^{\circ} \mathrm{C}$; IR $(\mathrm{KBr}): \mathrm{v} / \mathrm{cm}^{-1}=3345$, $1643,1600 \mathrm{~cm}^{-1}(\mathrm{NH}, \mathrm{C}=\mathrm{O}, \mathrm{N}=\mathrm{N}) ;{ }^{1} \mathrm{H}$ NMR $\left(\mathrm{CDCl}_{3}\right)$ : $\delta_{\mathrm{ppm}}=1.9\left(\mathrm{~s}, 3 \mathrm{H}, \mathrm{CH}_{3}\right), 4.2\left(\mathrm{~s}, 3 \mathrm{H}, \mathrm{CH}_{3}\right), 7.2-8.0(\mathrm{~m}$, $14 \mathrm{H}, \mathrm{Ar}), 14.1$ (s, 1H, NH); EIMS $(\mathrm{m} / \mathrm{z})(\%)=427\left(\mathrm{M}^{+}\right.$, 25). Anal. for $\mathrm{C}_{25} \mathrm{H}_{21} \mathrm{~N}_{3} \mathrm{O}_{2} \mathrm{~S}$ (427.5): calcd.: $\mathrm{C} 70.24, \mathrm{H}$ 4.95\%; found: C 70.24, H 4.95\%.

14d, Yield $86 \%$; $\mathrm{mp} 160^{\circ} \mathrm{C}$; IR $(\mathrm{KBr}): \mathrm{v} / \mathrm{cm}^{-1}=3445$, $1645,1515 \mathrm{~cm}^{-1}\left(\mathrm{NH}, \mathrm{C}=\mathrm{O}, \mathrm{NO}_{2}\right) ;{ }^{1} \mathrm{H}$ NMR $\left(\mathrm{CDCl}_{3}\right)$ : $\delta_{\mathrm{ppm}}=1.9\left(\mathrm{~s}, 3 \mathrm{H}, \mathrm{CH}_{3}\right), 7.3-7.58(\mathrm{~m}, 14 \mathrm{H}, \mathrm{Ar}), 14.7(\mathrm{~s}$, $1 \mathrm{H}, \mathrm{NH})$; $\operatorname{EIMS}(\mathrm{m} / \mathrm{z})(\%)=442\left(\mathrm{M}^{+}, 12\right)$. Anal. for $\mathrm{C}_{24} \mathrm{H}_{18} \mathrm{~N}_{4} \mathrm{O}_{3} \mathrm{~S}$ (442.5): calcd.: $\mathrm{C} 65.14, \mathrm{H} 4.10 \%$; found: C 65.14, H 4.00\%.

14e, Yield $69.5 \%$; $\mathrm{mp} 140^{\circ} \mathrm{C}$; IR $(\mathrm{KBr}): v / \mathrm{cm}^{-1}=3321$, 1622, $1594 \mathrm{~cm}^{-1}(\mathrm{NH}, \mathrm{C}=\mathrm{O}, \mathrm{N}=\mathrm{N}) ;{ }^{1} \mathrm{H}$ NMR $\left(\mathrm{CDCl}_{3}\right)$ : $\delta_{\mathrm{ppm}}=1.9\left(\mathrm{~s}, 3 \mathrm{H}, \mathrm{CH}_{3}\right), 7.2-7.6(\mathrm{~m}, 14 \mathrm{H}, \mathrm{Ar}), 13.85(\mathrm{~s}$, $1 \mathrm{H}, \mathrm{NH})$; $\operatorname{EIMS}(\mathrm{m} / \mathrm{z})(\%)=431\left(\mathrm{M}^{+}, 78\right)$. Anal. for $\mathrm{C}_{24} \mathrm{H}_{18} \mathrm{~N}_{3} \mathrm{OSCl}$ (431.9): calcd.: C 66.74, H 4.20\%; found: 
C $66.74, \mathrm{H} 4.00 \%$.

\subsubsection{1-Phenylamino-1-hydrazone-2-(arylazo)-2- benzoylethylene (15a)}

A mixture of $4 \mathbf{a}(3.55 \mathrm{~g}, 50 \mathrm{mmol})$ and hydrazine hydrate $(1.6 \mathrm{~g}, 50 \mathrm{mmol})$ in ethanol $(20 \mathrm{~mL})$ was stirred for $4 \mathrm{~h}$ at room temperature. The reaction mixture was then cooled and the solid product was filtered off and recrystallized from ethanol to give compound 15a.

Yield $65 \%$; $\mathrm{mp} 168^{\circ} \mathrm{C}$; IR $(\mathrm{KBr}): \mathrm{v} / \mathrm{cm}^{-1}=3550,3340$, $1640 \mathrm{~cm}^{-1}\left(\mathrm{NH}_{2}, \mathrm{NH}, \mathrm{C}=\mathrm{O}\right) ;{ }^{1} \mathrm{H}$ NMR (DMSO): $\delta_{\mathrm{ppm}}=$ $6.4\left(\mathrm{~s}, 2 \mathrm{H}, \mathrm{NH}_{2}\right), 7.2-7.8(\mathrm{~m}, 15 \mathrm{H}, \mathrm{Ar}), 12.7$ and 14.0 (s, $2 \mathrm{H}, 2 \mathrm{NH})$. Anal. for $\mathrm{C}_{21} \mathrm{H}_{19} \mathrm{~N}_{5} \mathrm{O}$ (357.4): calcd.: $\mathrm{C} 70.57$, H 5.35\%; found: C 70.50, H 5.30\%.

\subsubsection{Synthesis of Arylazopyrazoles 16a-e}

Method A: A mixture of 4a-e $(50 \mathrm{mmol})$, hydrazine hydrate $(1.6 \mathrm{~g}, 50 \mathrm{mmol})$ in DMF was refluxed for $4 \mathrm{~h}$. The reaction mixture then poured onto ice water $(200 \mathrm{~mL})$. The solid product was filtered off and recrystallized from ethanol-DMF (1:1) to give the corresponding derivatives 16a-e, respectively.

Method B: Refluxing the acyclic intermediate 15a in ethanol $(20 \mathrm{~mL})$ containing a catalytic amount of TEA for $3 \mathrm{~h}$ gave the pyrazole derivative $\mathbf{1 6 a}$.

16a, Yield $48 \%$; $\mathrm{mp} 256^{\circ} \mathrm{C}$; IR $(\mathrm{KBr}): v / \mathrm{cm}^{-1}=3235$ and $3192,1595 \mathrm{~cm}^{-1}$ (two NH, N=N); ${ }^{1} \mathrm{H}$ NMR (DMSO): $\delta_{\mathrm{ppm}}=7.3-8.0(\mathrm{~m}, 15 \mathrm{H}, \mathrm{Ar}), 10.0$ and $12.0(\mathrm{~s}, 2 \mathrm{H}, 2 \mathrm{NH})$; EIMS $(\mathrm{m} / \mathrm{z})(\%)=339\left(\mathrm{M}^{+}, 12\right)$. Anal. for $\mathrm{C}_{21} \mathrm{H}_{17} \mathrm{~N}_{5} \mathrm{~S}$ (339.4): calcd.: C 74.32, H 5.05\%; found: C 74.32, H $5.00 \%$.

16b, Yield $38 \%$; mp $228^{\circ} \mathrm{C}$; IR (KBr): $v / \mathrm{cm}^{-1}=3229$ and $3189,1597 \mathrm{~cm}^{-1}$ (two NH, N=N); ${ }^{1} \mathrm{H}$ NMR (DMSO): $\delta_{\mathrm{ppm}}=2.3\left(\mathrm{~s}, 3 \mathrm{H}, \mathrm{CH}_{3}\right), 7.0-8.2(\mathrm{~m}, 14 \mathrm{H}, \mathrm{Ar}), 10.1$ and $12.0(\mathrm{~s}, 2 \mathrm{H}, 2 \mathrm{NH})$; EIMS $(\mathrm{m} / \mathrm{z})(\%)=353\left(\mathrm{M}^{+}, 21\right)$. Anal. for $\mathrm{C}_{22} \mathrm{H}_{19} \mathrm{~N}_{5}$ (353.4): calcd.: C 74.77, H 5.42\%; found: C $74.77, \mathrm{H} 5.42 \%$.

16c, Yield $40 \%$; mp $210^{\circ} \mathrm{C}$; IR $(\mathrm{KBr}): v / \mathrm{cm}^{-1}=3230$ and 3195, 1597 (two $\mathrm{NH}, \mathrm{N}=\mathrm{N}$ ); ${ }^{1} \mathrm{H}$ NMR $\left(\mathrm{CDCl}_{3}\right): \delta_{\mathrm{ppm}}$ $=4.1\left(\mathrm{~s}, 3 \mathrm{H}, \mathrm{CH}_{3}\right), 7.0-7.7(\mathrm{~m}, 14 \mathrm{H}, \mathrm{Ar}), 10.2,13.1(\mathrm{~s}$, $2 \mathrm{H}, 2 \mathrm{NH})$. Anal. for $\mathrm{C}_{22} \mathrm{H}_{19} \mathrm{~N}_{5} \mathrm{O}$ (369.4): calcd.: $\mathrm{C} 71.53$, $\mathrm{H}$ 5.18\%; found: C 71.53, H 5.00\%.

16d, Yield $43 \%$; mp $200^{\circ} \mathrm{C}$; IR (KBr): $v / \mathrm{cm}^{-1}=3343$ and $3231,1597 \mathrm{~cm}^{-1}$ (two NH, N=N); ${ }^{1} \mathrm{H}$ NMR (DMSO): $\delta_{\mathrm{ppm}}=7.3-7.8(\mathrm{~m}, 14 \mathrm{H}, \mathrm{Ar}), 13.8$ and 14.2 for two (s, $1 \mathrm{H}, \mathrm{NH})$; $\operatorname{EIMS}(\mathrm{m} / \mathrm{z})(\%)=384\left(\mathrm{M}^{+}, 24\right)$. Anal. for $\mathrm{C}_{21} \mathrm{H}_{16} \mathrm{~N}_{6} \mathrm{O}_{2}$ (384.4): calcd.: $\mathrm{C} 63.62, \mathrm{H} 4.20 \%$; found: $\mathrm{C}$ $63.62, \mathrm{H} 4.20 \%$.

16e, Yield $33 \%$; mp $230^{\circ} \mathrm{C}$; IR $(\mathrm{KBr}): \mathrm{v} / \mathrm{cm}^{-1}=3187$ and $3117,1594 \mathrm{~cm}^{-1}$ (two NH, N=N); ${ }^{1} \mathrm{H}$ NMR (DMSO): $\delta_{\mathrm{ppm}}=7.3-8.0(\mathrm{~m}, 14 \mathrm{H}, \mathrm{Ar}), 13.7$ and $13.9(\mathrm{~s}, 2 \mathrm{H}, 2 \mathrm{NH})$; EIMS $(m / z)(\%)=373\left(\mathrm{M}^{+}, 37\right)$. Anal. for $\mathrm{C}_{21} \mathrm{H}_{16} \mathrm{~N}_{5} \mathrm{Cl}$ (373.8): calcd.: C 67.47, H 4.31\%; found: C 67.47, H $4.31 \%$.

\subsection{Antitumor Activity}

Cells of Ehrlich ascites tumor were obtained from National Cancer Institute, Cairo, Egypt. Animals, adult Swiss male albino mice $(20-25 \mathrm{~g})$ were procured from Pharmacology Faculty, Mansoura University, Egypt and used throughout this study. They were housed in microlon boxes in a controlled environment (temperature $25^{\circ} \mathrm{C}+$ $2^{\circ} \mathrm{C}$ and $12 \mathrm{~h} \mathrm{dark} /$ light cycle) with standard laboratory diet and water ad libitum (5-Fluorouracil $\rightarrow 20 \mathrm{mg} / \mathrm{kg}$ ).

\subsubsection{Animals Were Divided into Seven Groups as Follows}

All animals were inoculated with $2 \times 10^{6}$ cells/mouse on day "0" except normal group and treatment started $24 \mathrm{~h}$ after inoculation, at 2 doses of 50 and $250 \mathrm{mg} / \mathrm{kg} /$ day, i.p. The control group was treated with the same volume of $0.9 \%$ sodium chloride solution. All the treatments were given for nine days.

\subsubsection{Tumor Reducing Activity}

Ehrlich ascites tumor cells $(0.2 \mathrm{~mL})$ were injected into the mice peritoneal cavity and different concentrations (1 $\mathrm{mg} / \mathrm{mL}$ to $0.1 \mathrm{~mL} / \mathrm{mice}$ on day) of the drug (5 mice/group) were injected from day-1 to day-9 every day. Animals were observed for the development as ascites tumor and death due to tumor burdon. Life span \% I LS $=(\mathrm{T}-\mathrm{C}) / \mathrm{C} \times$ 100 , where $\mathrm{T}$ is the number of days the treated animals survived and $\mathrm{C}$ is the number of days control animals survived. \% I LS more than $25 \%$ was considered as significant [10].

\section{Results and Discussion}

\subsection{Chemistry}

We have been particularly interested in studying if reactions of such thiocarbamoyl might be extended to include more general synthesis of other classes of organic compounds and its utility as synthetic intermediate for the synthesis of new heterocyclic compounds. The present work reports on the synthesis of several new arylazothiophene and arylazopyrazole derivatives by the reaction of thiocarbamoyl of the type $\mathbf{4}$ with compounds containing an active methylene group in the presence of a base. Reactions of this type have not been reported previously, but they were found to give products in excellent yields under very mild conditions. Moreover, the resulting thiophene and pyrazole derivatives have latent functional substituents which have potential for further chemical transformations and new routes for the preparation of substituted thiophene and pyrazole derivatives with possible biological activity. Now, we have extended our synthetic program to the synthesis of otherwise inaccessible heterocyclic ring system utilizing phenyl isothiocyanate as a key starting material. It is known that a great variety 
of reactants bearing the $\mathrm{N}=\mathrm{C}=\mathrm{S}$ fragment undergoes cyclization on reaction with $\alpha$-halocarbonyl compounds to afford thiazoles, 2,3-dihydrothiazoles [11], which have been shown to exhibit antiprotozoal [12], and fungicidal properties [13].

Thus, the base-prompted reaction of the acidic methylene compound 1 with phenyl isothiocyanate in dry DMF at room temperature in basic medium led to the formation of the non-isolable intermediate 2 which gave thiocarbamoyl derivative $\mathbf{3}$ upon treatment with dilute $\mathrm{HCl}$. Treatment of $\mathbf{3}$ with aromatic diazonium salts in the presence of sodium acetate affected acetyl cleavage with the formation of arylazothiocarbamoyl derivatives 4a-e rather than the expected product 5 . This result is in agreement with the previously reported work [14-18], (Scheme 1).

Compound $\mathbf{3}$ was obtained according to the proposed following mechanism (Figure 1):

Assignment of the product $\mathbf{3}$ was based on elemental analysis, IR and ${ }^{1} \mathrm{H}-\mathrm{NMR}$ spectral data. ${ }^{1} \mathrm{H}$ NMR spectrum of 3 displayed multiplet signals at $\delta 7.1-7.5 \mathrm{ppm}$ for aromatic protons and exchangeable proton at 11.9 ppm for NH proton. On the other hand, the structure of the newly prepared hydrazone derivatives 4a-e was based on their correct elemental analysis and spectral data. The ${ }^{1} \mathrm{H}$ NMR spectrum of compound 4a displayed multiplet signals at $\delta 6.8-7.8 \mathrm{ppm}$ for aromatic protons and two exchangeable protons at $\delta 13.9$ and $16.4 \mathrm{ppm}$ for two $\mathrm{NH}$ protons. Compounds $4 \mathbf{a}-\mathbf{e}$ were obtained according to the proposed following mechanism (Figure 2):

In this paper, we describe a generally applicable extension of this synthetic approach, first reported by Hantzsch and Weber [19]. Thus, the base-prompted reaction of compounds $\mathbf{4 a}$ with potassium carbonate in dry DMF at room temperature affords the non-isolable intermediate 6a. Stirring of $\mathbf{6}$ with phenacyl bromide in DMF overnight yielded a product $\mathbf{7 a}$, which analyzed correctly for $\mathrm{C}_{29} \mathrm{H}_{21} \mathrm{~N}_{3} \mathrm{OS}$. The structure $7 \mathbf{a}$ was inferred from its spectral data. Its ${ }^{1} \mathrm{H}$ NMR spectrum showed two multiplet signals integrated for $(20 \mathrm{H})$ centered at 7.4 and 8.0 (aromatic protons) and a singlet $(1 \mathrm{H})$ at $\delta 10.2$. On shaking the compound with $\mathrm{D}_{2} \mathrm{O}$, the broad band signal at $\delta 10.2$ disappeared. Based on the foregoing data, structure 7a was assigned to this product. The structure $7 \mathbf{a}$ was further confirmed by alternative synthesis. Thus, it was found that, stirring of $\mathbf{4 a}$ with phenacyl bromide in the presence of potassium carbonate in ethanol at room temperature produced acyclic intermediate 8a. Structure 8a was suggested for the reaction product on the basis of both elemental and spectral analyses (c.f. Experimental part).

Refluxing 8a in ethanol with few drops of TEA led to the formation of a product identical in all respects (m.p. mixed m.p., IR) to 7a. Similarly, compounds 7b-e were synthesized by pathway (1), (Scheme 2).

The addition of two or more equivalents of ethyl bromoacetate, chloroacetonitrile, chloroacetone leads only to thiophenes 10, 12, and $\mathbf{1 4}$ in good yields. Thus, condensation of the intermediate salt with an equimolar amount of chloroacetyl chloride or with chloroacetic acid in ethanol, a product that analyzed for $\mathrm{C}_{25} \mathrm{H}_{23} \mathrm{~N}_{3} \mathrm{O}_{3} \mathrm{~S}$ was isolated in each case in good yield. The acyclic structure 9a was established on the basis of its IR spectrum that showed bands related to $\mathrm{NH}$ and $\mathrm{CO}$ functions (c.f. Experimental part).

Alternatively, treatment of the intermediate 6a with ethyl bromoacetate in ethanol gives a single product, which is identical in all respects to 9a (m.p. mixed m.p. and IR spectrum) (c.f. Experimental part). Refluxing of 9a in ethanol with a catalytic amount of TEA or leaving it in DMF containing potassium carbonate at room temperature overnight afforded the corresponding thiophene derivative 10a. In a similar manner, compounds 10a-e were prepared by pathway $\mathbf{1}$ ).

Similarly, when the intermediate potassium salt $\mathbf{6 a}$ is stirred with chloroacetonitrile in ethanol at room tem-

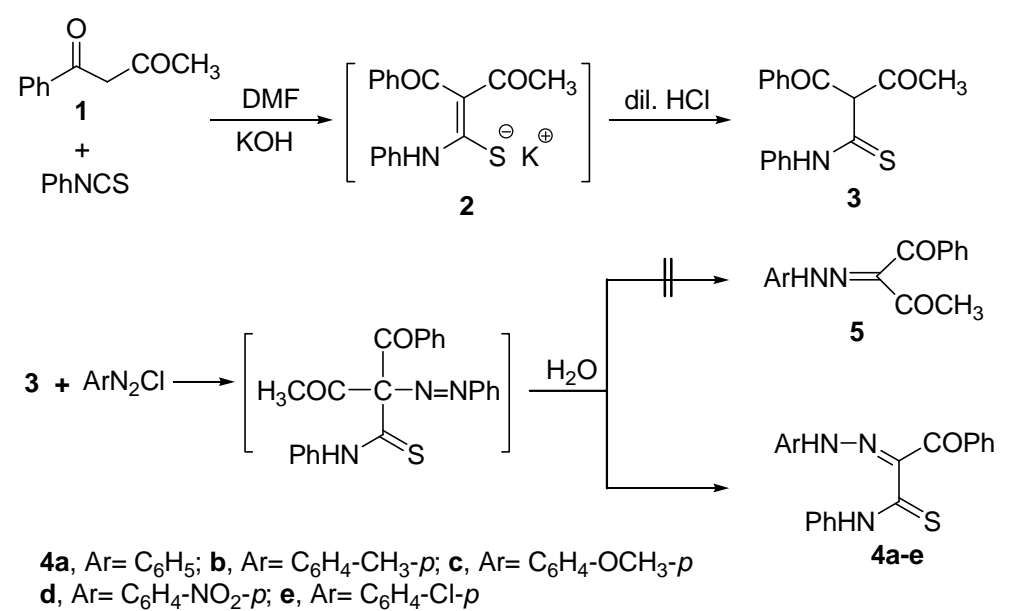

Scheme 1. Synthesis of thiocarbamoyl 3 and hydrazone derivatives $4 a-e$. 


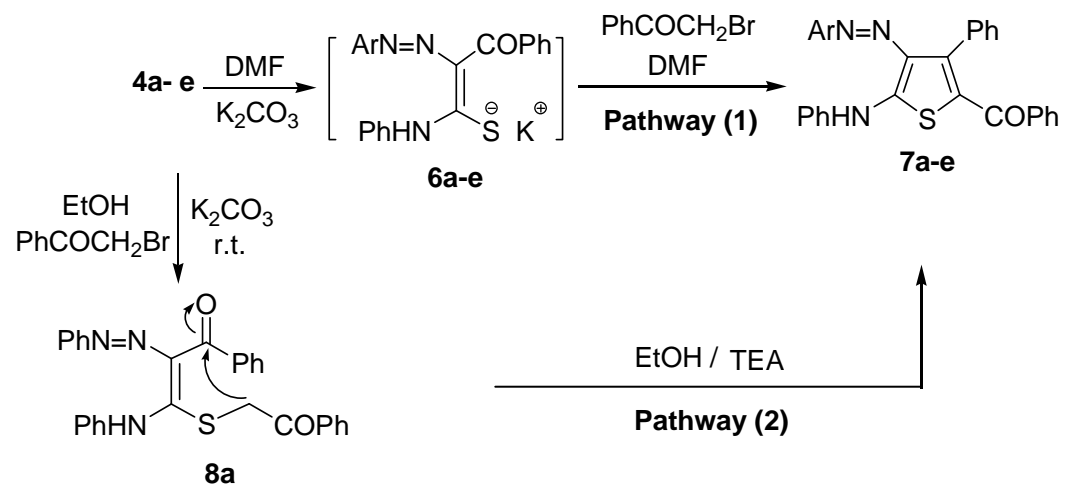

Scheme 2. Synthesis of thiophene derivatives 7a-e.

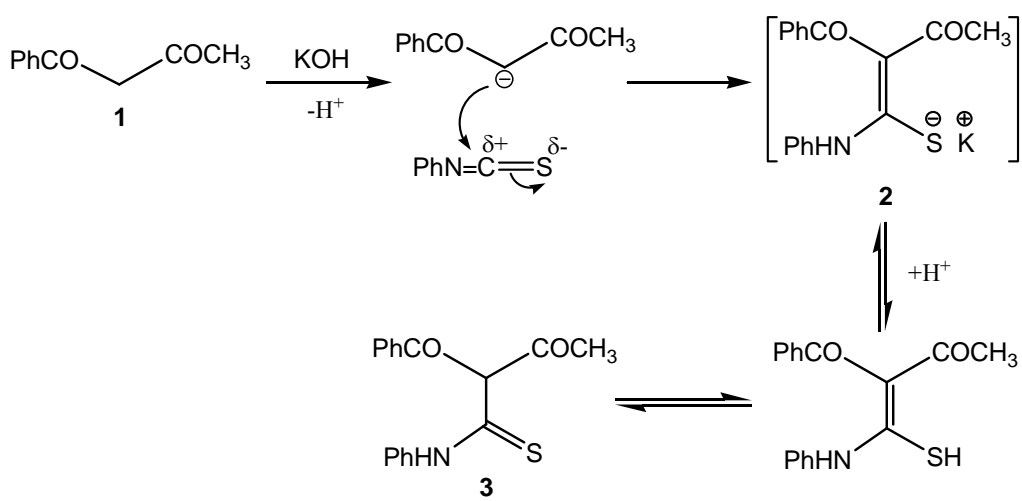

Figure 1. The proposed mechanism of formation of thiocarbamoyl derivative 3.

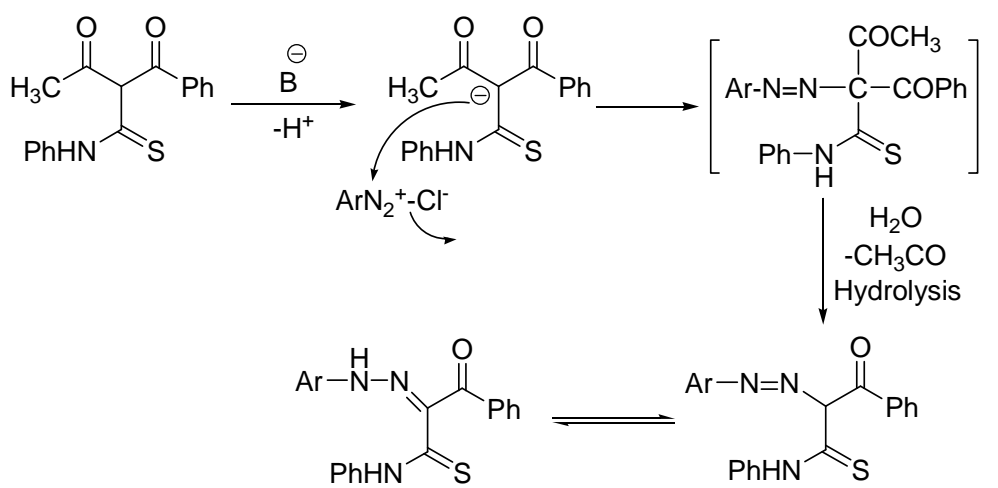

Figure 2. The proposed mechanism of formation of hydrazone derivatives 4a-e.

perature, the corresponding acyclic intermediate 11a is exclusively isolated in good yield. The structure $\mathbf{1 1}$ has been confirmed on the basis of elemental and spectral data (c.f. Experimental part). Furthermore, heating of the intermediate 11a in ethanol containing a catalytic amount of TEA affords the thiophene derivative 12a. The thiophene structure 12a was established on the basis of its IR spectrum which showed bands related to $\mathrm{NH}$ and $\mathrm{CN}$ functions. Its ${ }^{1} \mathrm{H} \mathrm{NMR}$ spectrum reveals broad signals at $\delta$ $14.2 \mathrm{ppm}(1 \mathrm{H}, \mathrm{NH})$. On the other hand, it has been found that 12a-e are directly formed by treatment of 6a-e with chloroacetonitrile in dimethylformamide and in the pre- sence of potassium carbonate at room temperature overnight by pathway (1), (Scheme 3).

Compound 6a reacted readily with chloroacetone in the presence of ethanol at room temperature to afford the acyclic intermediate 13a by $(\mathrm{KCl})$ elimination. Refluxing 13 in ethanol with a catalytic amount of TEA gave the thiophene derivative 14a whose structure was confirmed by its alternative synthesis. Thus, stirring 6a-e with chloroacetone in DMF overnight affords the thiophene derivative 14a-e in reasonably good yield, (Scheme 4).

On the other hand, treatment of the key intermediate 4b with hydrazine hydrate in DMF gave a single product 


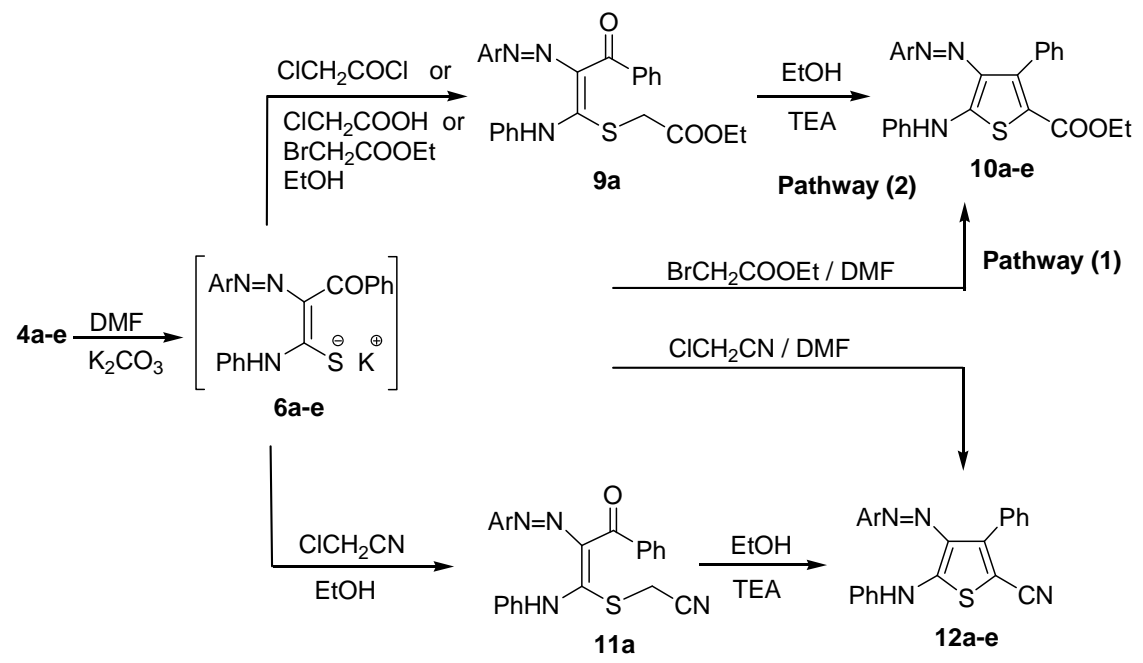

Scheme 3. Synthesis of thiophene derivatives 10a-e and 12a-e.

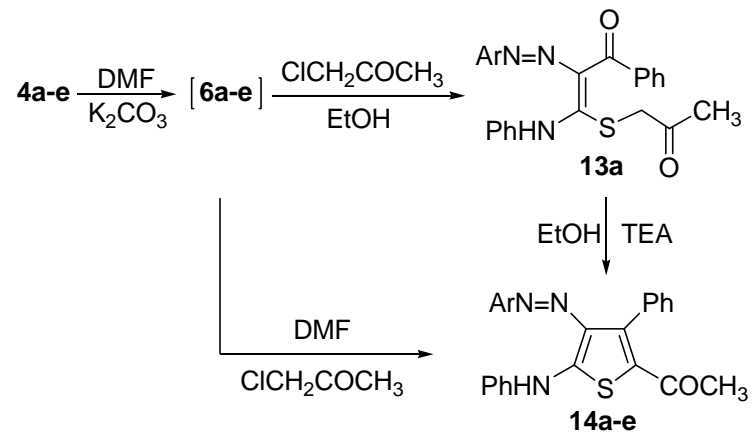

Scheme 4. Synthesis of thiophene derivatives 14a-e.

which analyzed correctly for $\mathrm{C}_{22} \mathrm{H}_{19} \mathrm{~N}_{5}$ (16b). The structure of 16b was inferred from its spectral data. The ${ }^{1} \mathrm{H}$ NMR spectrum revealed a singlet at $\delta 2.3$ assigned for the methyl protons, a broad band located at $\delta 10.1$ and 12.0 assignable to the $\mathrm{NH}$ protons, and a multiplet at $\delta$ 7.0 - 8.2, assigned for aromatic protons. The formation of 16a-e is assumed to proceed via the replacement of the $\mathrm{SH}$ group by the hydrazine moiety to give the intermediate 15 which then cyclized via the carbonyl group to afford the final isolable products 16a-e. In fact, the structure of 16 was further confirmed by alternative synthesis. Thus, it has been found that treatment of 4a with hydrazine hydrate for long time in ethanol produced the intermediate 15a. Refluxing 15a in ethanol containing a catalytic amount of TEA or in DMF lead to the formation of a product identical in all respects (m.p., mixed m.p., IR) with 16a [20]. Structure 15a is suggested for the reaction product on the basis of both elemental and spectral analyses. The ${ }^{1} \mathrm{H}$ NMR spectrum revealed a broad signal at $\delta 6.4$ assigned for $\mathrm{NH}_{2}$ protons, a multiplet at $\delta 7.2$ 7.8 for aromatic protons, and a singlet at $\delta 12.7$ and 14.0 ppm for NH protons, (Scheme 5).

These results indicate that the reaction of thiocar-

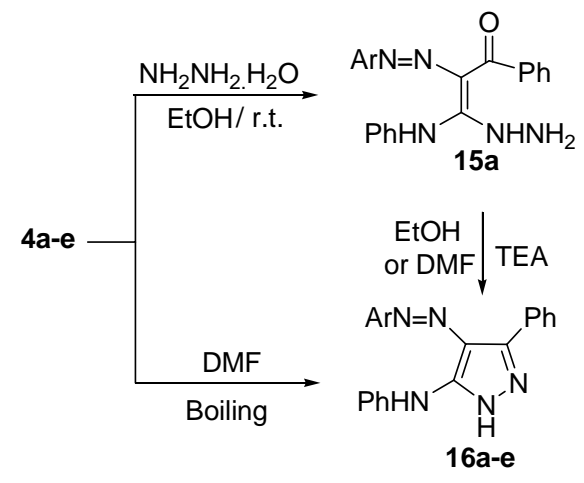

8, 9, 11, 13, 15a, $\mathrm{Ar}=\mathrm{Ph}$

7, 10, 12, 14, 16a, $\mathrm{Ar}=\mathrm{C}_{6} \mathrm{H}_{5} ; \mathbf{b}, \mathrm{Ar}=\mathrm{C}_{6} \mathrm{H}_{4}-\mathrm{CH}_{3}-p$;

c, $\mathrm{Ar}=\mathrm{C}_{6} \mathrm{H}_{4}-\mathrm{OCH}_{3}-p ; \mathbf{d}, \mathrm{Ar}=\mathrm{C}_{6} \mathrm{H}_{4}-\mathrm{NO}_{2}-p ; \mathbf{e}, \mathrm{Ar}=\mathrm{C}_{6} \mathrm{H}_{4}-\mathrm{Cl}-p$

Scheme 5. Synthesis of arylazopyrazole derivatives 16a-e.

bamoyls and bifunctional reagents provides an excellent route for the synthesis of five, otherwise not easily accessible arylazothiophenes and pyrazoles. The compounds synthesized will be subjected to biological testing.

\subsection{Biological Activity}

\subsubsection{Discussion}

\subsubsection{Effect of Drugs on the Viability of Ehrlich Ascites Cells in Vitro}

To examine whether these substances have a direct cytotoxic effect on Ehrlich ascites cells (EAC) viability, the percentage of viable cells was estimated by the trypan blue [21], exclusion test. The desired concentration of tumor cells $\left(2 \times 10^{6}\right.$ cells per $\left.0.2 \mathrm{~mL}\right)$ was obtained by dilution with saline ( $0.9 \%$ sodium chloride solution). Viability of tumor cells obtained and used in this experiment was always higher than $90 \%$. Below this percentage, the cells were discarded and the entire procedure was 
repeated. Twenty five sulfur containing compounds were tested for cytotoxicity against EAC in vitro. Results for the $\left(\mathrm{ED}_{50 \times 10^{3}}\right),\left(\mathrm{ED}_{25 \times 10^{3}}\right)$ and $\left(\mathrm{ED}_{10 \times 10^{3}}\right)$ values of the active compounds are summarized in Table 1. Compounds 4a, c, 7c and 10c displayed moderate cytotoxicity, whereas 7e and 10d were the most potent with $\left(\mathrm{ED}_{25 \times 10^{3}}\right)$. The other rest of compounds showed weak to no activity. Thus, it would appear that introducing thiophene moiety enhances the cytotoxic properties. By comparing the cytotoxicity results in Table $\mathbf{1}$, the following structureactivity relationships (SARs) were drawn: 1) Converting the thiocarbamoyl moiety to the corresponding thiophene (7c, e and 10c, d) led to increase cytotoxicity against EAC. Compounds $7 \mathbf{e}$ and 10d were the most active, whereas, compounds 7c and 10c exhibited good activity. Thus, the ring substituents affected the activity in the thiophene derivatives; 2) The most of compounds containing electronedonating groups were very weak or completely inactive at $\left(\mathrm{ED}_{25 \times 10^{3}}\right)$ than the compounds containing electronewithdrawing groups. Thus, the position and nature of substituents on the structure of thiophene derivatives seem to modulate antitumor activity. The reliable criteria for judging the value of any anticancer drug are prolongation of life span and decrease of WBC from blood $[8,9]$. The results of the present study showed an antitumor effect of the compounds against EAC in Swiss albino mice (Table 2).

\subsubsection{Effect of Compound 10d on Survival Time [22]}

The mean survival time (MST) of each group consisting of seven mice was noted. The antitumor efficacy was compared with that of 5-fluorouracil (5-FU), for 9 days. The MST of the treated groups was compared with that of the control group using the following calculation: \% Increase in life span over control $=(\mathrm{MST}$ of treated group-MST of control group) $\times 100-100$, where MST= survival time (days of each mouse in a group)/Total no. of mice (Table 2).

\subsubsection{Effect of the Sulfur Containing Compounds on Hematological Parameters}

To examine the influence of the tested compounds on the hematological status of EAC-bearing mice, a comparison was made among the following groups $(n=7)$ of mice on the $14^{\text {th }}$ day after inoculation. The groups comprised of 1 ) tumor-bearing mice; 2) tumor-bearing mice treated for the first 9 days; and 3) control mice (normal). Blood was drawn from each mouse by the retro orbital plexus method and the white blood cell count (WBC), red blood cell count (RBC) and hemoglobin were determined. From each group take $100 \mu \mathrm{M}$ sample of Ehrlich ascites cells (from three mice) and make 20 fold dilutions in saline. The cells were stained by Giemsa stain and measure the number of viable cells under microscope. The
Table 1. Effect of sulfur containing compounds on the viability of Ehrlich ascites cells (EAC) in vitro assay.

\begin{tabular}{|c|c|c|c|}
\hline \multirow{2}{*}{ Compound } & \multicolumn{3}{|c|}{ Dead \% } \\
\hline & $\mathrm{ED}_{50 \times 10^{3}} \mu \mathrm{M}$ & $\mathrm{ED}_{25 \times 10^{3}} \mu \mathrm{M}$ & $\mathrm{ED}_{10 \times 10^{3}} \quad \mu \mathrm{M}$ \\
\hline 5-flu & $96.3 \%$ & $0 \%$ & $0 \%$ \\
\hline $4 a$ & $100 \%$ & $9.1 \%$ & $0 \%$ \\
\hline $4 b$ & $100 \%$ & $0 \%$ & $0 \%$ \\
\hline $4 c$ & $100 \%$ & $9.1 \%$ & $3.2 \%$ \\
\hline $4 d$ & $100 \%$ & $4.5 \%$ & $0 \%$ \\
\hline $4 e$ & $100 \%$ & $0 \%$ & $0 \%$ \\
\hline $7 a$ & $100 \%$ & $0 \%$ & $10 \%$ \\
\hline $7 b$ & $100 \%$ & $0 \%$ & $0 \%$ \\
\hline $7 c$ & $100 \%$ & $11.8 \%$ & $0 \%$ \\
\hline $7 d$ & $100 \%$ & $0 \%$ & $0 \%$ \\
\hline $7 e$ & $100 \%$ & $53.8 \%$ & $3.3 \%$ \\
\hline $10 a$ & $100 \%$ & $0 \%$ & $0 \%$ \\
\hline $10 \mathrm{~b}$ & $100 \%$ & $0 \%$ & $0 \%$ \\
\hline $10 \mathrm{c}$ & $100 \%$ & $21 \%$ & $0 \%$ \\
\hline 10d & $100 \%$ & $53.8 \%$ & $3.8 \%$ \\
\hline $10 \mathrm{e}$ & $68.4 \%$ & $4 \%$ & $0 \%$ \\
\hline $12 a$ & $100 \%$ & $0 \%$ & $0 \%$ \\
\hline $12 b$ & $100 \%$ & $8 \%$ & $0 \%$ \\
\hline $12 c$ & $100 \%$ & $0 \%$ & $0 \%$ \\
\hline 12d & $100 \%$ & $0 \%$ & $0 \%$ \\
\hline $12 e$ & $100 \%$ & $3.6 \%$ & $0 \%$ \\
\hline $14 a$ & $94.4 \%$ & $0 \%$ & $0 \%$ \\
\hline $14 b$ & $100 \%$ & $0 \%$ & $0 \%$ \\
\hline $14 c$ & $100 \%$ & $0 \%$ & $0 \%$ \\
\hline $14 d$ & $100 \%$ & $4.3 \%$ & $0 \%$ \\
\hline $14 e$ & $100 \%$ & $0 \%$ & $0 \%$ \\
\hline
\end{tabular}

Where, ED is the concentration of compounds in $\mu \mathrm{M}$.

Table 2. In vivo cytotoxicity of 10d using EAC assay.

\begin{tabular}{|c|c|c|c|c|c|}
\hline $\begin{array}{c}\text { Test } \\
\text { Group }\end{array}$ & $\begin{array}{c}\mathrm{Hb} \\
12-16 \\
\mathrm{~g} / \mathrm{dl}\end{array}$ & $\begin{array}{c}\text { HCT } \\
35 \%-50 \% \\
\text { (hematocrit) }\end{array}$ & $\begin{array}{c}\text { WBCs } \\
4000- \\
11,000 \\
/ \mathrm{cmm}\end{array}$ & $\begin{array}{l}\text { Ehrlish cells } \\
\text { count } \mathrm{mil} / \mathrm{ml}\end{array}$ & MST/day \\
\hline${ }^{*}$ Normal & 13.9 & 53.6 & 8.4 & - & - \\
\hline${ }^{* *}$ Control & 8.7 & 35.5 & 38.6 & 220.0 & 9.1 \\
\hline 5-FU & 10.0 & 42.3 & 13.8 & 123.0 & 16.7 \\
\hline $\begin{array}{c}\text { Compound } \\
\text { (10d) }\end{array}$ & 9.0 & 39.7 & 26.0 & 172.8 & 12.8 \\
\hline
\end{tabular}

*Normal test: without EAC; ${ }^{* *}$ Control test: with EAC. 
viable cells those, which did not take up the stain, where the dead cells (stained cells).

From Table 2; it was noticed that, 1 ) in the $5^{\text {th }}$ day after inoculation of Ehrlich cells in mice, increase in body weight and ascites was observed clearly, also the mice became slow and inactive; 2) Mice received compound 10d and 5-FU were more protected against ascites and increase in weight than control mice; 3) Mice received compound 10d showed slight toxic symptoms such as dizziness, dirty look; erection of tail, slow movement. Also the liver of animals was pale and slightly enlarged; 4) Percentage increase of life span over control showed to be high in mice treated with total extracts; 5) Mice that received compound 10d showed comparable results to 5-FU; 6) Hematological parameters of tumor bearing mice on Day 14 showed significant changes when compared with normal mice; 7) Total WBC count was found to increase with a reduction in the hemoglobin content and increase of RBCs; 8) Compound 10d and 5-FU showed minimal ascites and slight increase in body weight unlike control group.

\section{Conclusion}

Modification of thiocarbamoyl produced thiophene compounds with potential for further development as anticancer agents. Based on these preliminary screening results, compounds 7c, e and 10c, d showed significant activity in certain cancer cell and have been targeted for further studies, compound 10d is more effective and showed the highest activity. Additional research, including mode of action studies, is planned to accurately establish relative activity for (SAR) and rational design. Recently, the cancer chemopreventive effects of thiophene have been intensively investigated. Thiophene exhibited pronounced antitumor activity by triggering apoptosis inhuman tumor cells [23]. Studies are underway to investigate the apoptosis inducing activity of compounds found to be cytotoxic in this study.

\section{Acknowledgements}

To Prof. Dr. Farid A. Badria, Head of Pharmacognosy Department, Faculty of Pharmacy for microbiological screening, he is greatly acknowledged.

\section{REFERENCES}

[1] A. K. Mukerjee and R. Ashare, "Isothiocyanates in the Chemistry of Heterocycles," Chemical Review, Vol. 91, No. 1, 1991, pp. 1-24. doi:10.1021/cr00001a001

[2] S. I. El-Desoky, H. A. Etman, S. B. Bondock, A. A. Fadda and M. A. Metwally, "Utility of Isothiocyanates in Heterocyclic Synthesis," Sulfur Letter, Vol. 25, No. 5, 2002, pp. 199-205. doi:10.1080/02786110214496
[3] S. I. El-Desoky, S. B. Bondock, H. A. Etman, A. A. Fadda and M. A. Metwally, "Synthesis of Some New Thiazole Derivatives of Pharmaceutical Interest," Sulfur Letter, Vol. 26, No. 3, 2003, pp. 127-135. doi:10.1080/0278611031000095331

[4] K. N. Zelenin, O. V. Solod, V. V. Alekseev, T. I. Pekhk, O. B. Kuznetsova, P. B. Terent'ev and A. G. Kalandarishvili, "Synthesis of Pyrazole, 1,3,4-Thiadiazole, and 1,2,4-Triazole Derivatives by Condensatoin of 1,3-Dioxo Compounds with Thiosemicarbazide Derivatives," Journal Chememistry Heterocyclic Compounds, Vol. 26, 2004, pp. 1051-1060. doi:10.1007/BF00472492

[5] M. E. A. Zaki, A. A. Fadda, Kh. Samir and F. A. Amer, "Nitriles in Organic Synthesis: A Convenient Route to Some Heterocycles Incorporating a Benzothiazole Moiety," Phosphorus, Sulfur and Silicon and the Related Elements, Vol. 181, No. 8, 2006, pp. 1815-1823. doi: $10.1080 / 10426500500542828$

[6] A. A. Fadda, H. A. Etman, A. A. Sarhan and S. A. El-Hadidy, "Synthesis of Novel 1,2,3,4-Tetrahydrocarbazole Derivatives of Biological Interest," Phosphorus, Sulfur and Silicon and the Related Elements, Vol. 185, No. 3, 2010, pp. 526-536. doi:10.1080/10426500902839863

[7] A. A. Fadda, M. Hammouda, E. M. Afsah and A. A. Hanash, "Nitriles in Organic Synthesis: Synthesis of New Benzothiazole Derivatives of Biological Interest," Phosphorus, Sulfur and Silicon and the Related Elements, Vol. 185, No. 2, 2010, pp. 433-446. doi:10.1080/10426500902812498

[8] A. El-Shafei, A. A. Fadda, A. M. Khalil, T. A. E. Ameen and F. A. Badria, "Synthesis, Antitumor Evaluation, Molecular Modeling and Quantitative Structure-Activity Relationship (QSAR) of Some Novel Arylazopyrazolodiazine and Triazine Analogs," Bioorganic \& Medicinal Chemistry, Vol. 17, No. 14, 2009, pp. 5096-5105. doi:10.1016/j.bmc.2009.05.053

[9] A. A. Fadda, F. A. Badria and K. M. El-Attar, "Synthesis and Evaluation of Curcumin Analogues as Cytotoxic Agents," Medicinal Chemistry Research, Vol. 19, 2010, pp. 413-430. doi:10.1007/s00044-009-9199-3

[10] R. Kuttan, P. Bhanumathy, K. Nirmala and M. C. George, "Potential Anticancer Activity of Turmeric (Curcuma longa)," Cancer Letter, Vol. 29, 1985, pp. 197-202. doi:10.1016/0304-3835(85)90159-4

[11] R. A. Tapia, L. Alegria, C. D. Pessoa, C. Salas, M. J. Cortés, J. A. Valderrama, M.-E. Sarciron, F. Pautet, N. Walchshofer and H. Fillion, "Synthesis and Antiprotozoal Activity of Naphthofuranquinones and Naphthothiophenequinones Containing a Fused Thiazole Ring," Bioorganic \& Medicinal Chemistry, Vol. 11, No. 10, 2003, pp. 2175-2182. doi:10.1016/S0968-0896(03)00122-6

[12] H. Saraçoglu, C. Davran, S. Soylu, Ö. Andaç, H. Bati and N. Çaliskan, "3-[2,4-Dinitrophenyl)hydrazono]butane-2one Oxime," Acta Crystallography, Vol. E60, 2004, pp. 1307-1309.

[13] R. F. Japp and F. Klingemann, "Ueber Benzolazo- und Benzolhydrazofettsäuren," Chemische Berichte, Vol. 20, No. 4, 1887, pp. 2942-2944. 


\section{doi:10.1002/cber. 188702002165}

[14] V. P. Litvinov, "Thienopyrimidines: Synthesis, Properties, and Biological Activity," Journal Russian Chemical Bulletin, Vol. 53, No. 3, 2004, pp. 487-516. doi:10.1023/B:RUCB.0000035630.75564.2b

[15] M. A. Metwally, E. Abdel-Latif and S. Bondock, "Thiocarbamoyl Derivatives as Synthons in Heterocyclic Synthesis," Sulfur Chemistry, Vol. 28, No. 4, 2007, pp. 431466. doi:10.1080/17415990701397767

[16] E. Abdel-Latif and F. A. Amer, "Synthesis of Some 4-Arylazo-3-hydroxythiophene Disperse Dyes for Dyeing Polyester Fabrics," Monatshefte für Chemie, Vol. 139, No. 5, 2008, pp. 561-567. doi:10.1007/s00706-007-0722-2

[17] M. A. Metwally, E. Abdel-Latif and F. A. Amer, "Synthesis and Reactions of Some Thiocarbamoyl Derivatives," Journal of Sulfur Chemistry, Vol. 26, No. 3, 2003, pp. 119-126.

[18] A. Hantzsch and H. Weber, "Pyridins der Thiophenreihe," Chemische Berichte, Vol. 20, 1887, pp. 3118-3132. doi:10.1002/cber. 188702002200

[19] A. A. Fadda, F. A. Amer, M. E. A. Zaki and Kh. Samir, "Revised Synthesis of Some New Derivatives of Biological Interest 2-Heterocyclic Benzothiazolyl Derivatives of Biological Interest," Phosphorus, Sulfur and Silicon and the Related Elements, Vol. 155, 1999, pp. 59-66. doi:10.1080/10426509908044970

[20] K. R. Sheeja, G. Kuttan and R. Kuttan, "Cytotoxic and Antitumour Activity of Berberin," Amala Research Bulletin, Vol. 17, 1997, pp. 73-76.

[21] P. Sur and D. K. Ganguly, "Tea Plant Root Extract (TRE) as an Antineoplastic Agent," Planta Medicinal, Vol. 60, 1994, pp. 106-109. doi:10.1055/s-2006-959427

[22] I. Jarak, M. Kralj, I. Piantanida, L. Šuman, M. Žinić, K. Pavelić and G. Karminski-Zamola, "Novel Cyano- and Amidino-Substituted Derivatives of Thieno[2,3-b]- and Thieno[3,2-b]thiophene-2-carboxanilides and Thieno-[3', $\left.2^{\prime}: 4,5\right]$ thieno- and Thieno[2',3':4,5]thieno [2,3-c]quinolones: Synthesis, Photochemical Synthesis, DNA Binding, and Antitumor Evaluation," Bioorganic \& Medicinal Chemistry, Vol. 14, No. 8, 2006, pp. 2859-2868. doi:10.1016/j.bmc.2005.12.004

[23] T. Galbadage and P. S. Hartman, "Repeated Temperature Fluctuation Extends the Life Span of Caenorhabditis Elegans in a Daf-16-Dependent Fashion," Ageing and Development, Vol. 129, No. 9, 2008, pp. 507-514. doi:10.1016/j.mad.2008.04.012 